\title{
AIDS incidence trends at presentation and during follow-up among HIV-at-risk populations: a 15-year nationwide cohort study in Taiwan
}

Chun-Yuan Lee ${ }^{1,2,3}$, I-An Jen ${ }^{4}$, Yu-Ching Lan ${ }^{5}$, Yung-Feng Yen ${ }^{3,6,7,8}$, Pei-Hung Chuang ${ }^{9,10}$, Marcelo Chen ${ }^{11,12}$, Yun Lee ${ }^{3}$ and Yi-Ming A. Chen ${ }^{3,13^{*}}$

\begin{abstract}
Background: Although Taiwan has implemented several important interventions for various HIV-at-risk populations to combat the HIV epidemic, little is known regarding AIDS incidence at presentation and during follow-up among the various HIV-at-risk populations in Taiwan. A better understanding of AIDS incidence trends would help improve patient care and optimize public health strategies aimed at further decreasing HIV-related morbidity and mortality.

Methods: Data from Taiwan Centers for Disease Control-operated Notifiable Diseases Surveillance System and Taiwan National Health Insurance Research Database (1998-2012) was divided into five cohort periods (consecutive 3-year groups). Logistic regression was employed to identify factors associated with AIDS incidence at presentation. Time-dependent Cox regression was used to identify factors associated with AIDS incidence during the follow-up period.

Results: Of 22,665 patients [mean age: 32 years; male (93.03\%)], 6210 (27.4\%) had AIDS incidence over 2 (1.16) [median (interquartile range)] years of follow-up. AIDS developed in $\leq 3$ months of HIV diagnosis in $73.6 \%$ AIDS patients. AIDS incidence trends at presentation and during follow-up differed according to HIV transmission routes over the five periods: AIDS at presentation increased in the sexual contact groups $(P<0.001$ for homosexuals/ heterosexuals; 0.648 for bisexuals) but decreased to a nadir in period 3 and then increased slightly in period 5 $(P<0.001)$ in people who injected drugs (PWIDs). AIDS incidence during the follow-up period increased from period 1 to a peak in period 3 or 4 , before declining slightly in period 5 , in the sexual contact groups $(P<0.001$ for homosexuals/heterosexuals; 0.549 for bisexuals). However, it increased throughout the five periods in PWIDs $(P<0.001)$. Older age, sexual contact group versus PWIDs, high versus low income level, cohort periods, and HIV diagnosis regions helped predict AIDS at presentation and during follow-up.
\end{abstract}

Conclusions: Disparities in AIDS incidence trends in various HIV-at-risk populations reflect different sociodemographic variables of HIV exposure and the adopted HIV prevention strategies. This study suggests the urgent need for tailored strategies aimed at specific populations at presentation and during follow-up.

Keywords: Acquired immunodeficiency syndrome, Antiretroviral therapy, HIV, Homosexual, Heterosexual

\footnotetext{
* Correspondence: arthur@kmu.edu.tw

${ }^{3}$ Center for Infectious Disease and Cancer Research (CICAR), Kaohsiung

Medical University, No.100, Tzyou 1st Road, Kaohsiung 807, Taiwan

${ }^{13}$ Department of Microbiology and Institute of Medical Research, College of

Medicine, Kaohsiung Medical University, Kaohsiung, Taiwan

Full list of author information is available at the end of the article
}

(c) The Author(s). 2018 Open Access This article is distributed under the terms of the Creative Commons Attribution 4.0 International License (http://creativecommons.org/licenses/by/4.0/), which permits unrestricted use, distribution, and reproduction in any medium, provided you give appropriate credit to the original author(s) and the source, provide a link to the Creative Commons license, and indicate if changes were made. The Creative Commons Public Domain Dedication waiver (http://creativecommons.org/publicdomain/zero/1.0/) applies to the data made available in this article, unless otherwise stated. 


\section{Background}

HIV-related mortality and morbidity rates have substantially decreased because of global efforts to improve access to antiretroviral therapy [1, 2]; however, high acquired immunodeficiency syndrome (AIDS) incidence, especially during the early phase of the HIV care, remains challenging. Although global campaigns encourage earlier HIV testing, substantial numbers of HIV-infected individuals do not enter healthcare systems until later stages, even when AIDS-defining events occur [3-5].

AIDS incidence is associated with higher HIVrelated morbidity and mortality rates [5-8], higher HIV transmission rates to sexual partners $[9,10]$, increase health expenses [7, 11], and impaired immunological response to highly active antiretroviral therapy (HAART) [12]. Therefore, ongoing surveillance to monitor AIDS incidence trends at presentation and during follow-up and the characterization of the associated risk factors is essential. AIDS incidence at presentation indicates late presentation of HIV [3-5], whereas AIDS incidence during follow-up is related to access to HAART, thresholds of initiation of HAART, regimens of HAART, and adherence to HIV care. Therefore, a better understanding of AIDS incidence trends at presentation and during follow-up would help improve patient care and optimize public health strategies aimed at further decreasing HIV-related morbidity and mortality.

Since the first HIV case in Taiwan was reported in 1984 , a total of 33,423 cases were reported until the end of 2016. Of these, 15,418 patients (46.1\%) developed full-blown AIDS [13]. Taiwan has implemented several important interventions for various HIV-at-risk populations to combat the HIV epidemic [13]. These include free HAART and anonymous voluntary counseling and testing (VCT) for HIV among at-risk populations since 1997, harm-reduction programs among intravenous drug users (PWIDs) since 2005, and an HIV case management program since 2007. However, little is known regarding AIDS incidence trends at presentation and during follow-up among the various HIV-at-risk populations in Taiwan [14-16].

In this nationwide cohort study, we employed data from the Taiwan Centers for Disease Control (TCDC)-operated Notifiable Diseases Surveillance System (NDSS) and Taiwan National Health Insurance Research Database (NHIRD) (reference period: 1998-2012) to analyze AIDS incidence trends at presentation (thus reflecting issues of late presentation of HIV) and during follow-up (thus reflecting issues of access to HAART, thresholds of initiation of HAART, regimens of HAART, and adherence to HIV care) among various HIV-at-risk populations over five cohort periods.

\section{Methods}

\section{Data sources}

Data were obtained from the TCDC-operated NDSS and NHIRD databases. The TCDC-operated NDSS provides a national web-based platform for reporting and monitoring several communicable diseases, including HIV and AIDS. Since 1984, both HIV infection and AIDS are notifiable diseases by law in Taiwan. Once HIV infection cases are confirmed on the basis of positive HIV-1 western blot or polymerase chain reaction analysis results, diagnosing healthcare providers are required to report newly confirmed HIV-infection cases to the TCDC-operated NDSS $\leq 24 \mathrm{~h}$ of diagnosis. According to the United States CDC 1993 AIDS case definition [17], the reporting of AIDS is also mandatory within $24 \mathrm{~h}$. Patients' information, including identification number, date of birth, sex, home address, HIV-transmission route, date of HIV diagnosis, and AIDS incidence must be reported to TCDC-operated NDSS by diagnosing healthcare providers.

Taiwan National Health Insurance is a mandatory universal health insurance program that has provided comprehensive medical care to $>99 \%$ Taiwanese citizens since 1995 [18]. NHIRD, a large-scale, public database derived from the national health insurance system, contains registration files and original claims data for reimbursement. Researchers can apply for access to associated data from TCDC-operated NDSS and NHIRD. The data is anonymized before release.

\section{Study design and setting}

First, new-HIV-infection cases from January 1, 1998 to December 31, 2012 were directly selected from NDSS. The selected cases were then linked to the Taiwan NHIRD. Following exclusion criteria were used: age $<15$ years; sex category: unknown; incomplete data. To analyze AIDS incidence trends, the enrolled patients were stratified according to HIV diagnosis date into five (3-year) cohort periods: period 1 (January 1, 1998-December 31, 2000); period 2 (January 1, 2001-December 31, 2003); period 3 (January 1, 2004-December 31, 2006); period 4 (January 1, 2007-December 31, 2009); and period 5 (January 1, 2010-December 31, 2012). Each enrolled HIV patient was followed up until 24 months from the date of reporting to NDSS, or AIDS incidence, or death, whichever occurred first. Next, the sociodemographic variables, HIV-related variables, and associated outcomes were compared between the cohort periods. Finally, AIDS incidence trends at presentation and during the follow-up periods among various HIV-at-risk populations and their associated factors were analyzed. 


\section{Variable collection and definitions}

The control variables were sociodemographic variables, comorbidities, HIV diagnosis region, and cohort periods. Urbanization was categorized as residence in an urban or rural area [19]. Insurer income level was categorized into three levels: low $(\leq 19,200$ New Taiwan Dollars [NTD]), intermediate (19,201-40,000 NTD), and high $(\geq 40,000 \mathrm{NTD})$ according to the average monthly income of the insured person [19]. For insured patients aged between 15 to 20 years, who have no income, the insured income indicates their parents' income. The comorbidities in the study population were defined by NHIRD, and a person was considered to have comorbidities when the comorbidities were diagnosed in an inpatient setting or at $\geq 3$ outpatient visits before HIV diagnosis [19].

HAART initiation was defined as the first recorded date of prescription of $\geq 3$ antiretroviral agents ( $\geq 2$ classes) or a triple nucleoside/nucleotide reverse transcriptase inhibitor regimen.

AIDS incidence at presentation was defined as the frequency of patients who developed AIDS $\leq 3$ months of HIV diagnosis [4]. AIDS incidence during follow-up period was defined as those who did not develop AIDS $\leq 3$ months of HIV diagnosis, but developed AIDS thereafter during the follow-up period. HIV diagnosis region was defined as the area from which physicians reported HIV diagnosis to TCDC, and was categorized into one of six administrative areas according to the TCDC NDSS: Taipei area, northern Taiwan, central Taiwan, southern Taiwan, Kaoping area, and eastern Taiwan.

\section{Primary and secondary outcomes}

The primary outcomes were trends of AIDS incidence at presentation and during the follow-up period among the targeted HIV-at-risk populations over the five cohort periods. The secondary outcomes were factors associated with AIDS incidence at presentation and during the follow-up period.

\section{Statistical analysis}

The values of categorical variables among the five cohort periods were compared using the Pearson's $x^{2}$ or Fisher's exact test. The values of continuous variables were compared using the analysis of variance. The trend analyses of AIDS incidence at presentation and during the follow-up period through five follow-up periods among HIV-at-risk populations were performed using the Cochran-Armitage trend test with modified ridit scores.

Univariable analysis and multivariable logistic regression were employed to identify factors associated with AIDS incidence at presentation. All variables used in univariable analysis were selected for subsequent multivariable logistic regression.
The probability of AIDS-free survival stratified by the cohort period in different HIV-at-risk populations was estimated using the Kaplan-Meier survival curves and log-rank testing. Time-dependent Cox regression was used to identify factors associated with AIDS incidence during the follow-up period. In these models, HAART was regarded as a time-dependent covariable, whereas other confounders, such as sociodemographic variables (age, sex, urbanization, and income level); HIV transmission route; comorbidities; HIV diagnosis region; and cohort period-collected at baseline-were regarded as fixed covariates.

Further, 95\% confidence intervals (CIs) of odds ratios (ORs) or hazard ratios (HRs) were calculated to estimate each variable's effects and the direction of associations. All tests were two-tailed, and $P<0.05$ was considered significant. All data management and analyses were performed using the SAS 9.4 software package (SAS Institute, Cary, NC, USA).

\section{Results \\ Participant selection}

A total of 22,665 HIV patients were enrolled: 1373 from period 1; 2262 from period 2; 7774 from period 3; 5288 from period 4; and 5968 from period 5 (Fig. 1).

\section{Characteristics of study participants}

Table 1 summarizes the baseline sociodemographic variables, comorbidities, HIV diagnosis region, and HIVrelated outcomes for the five-period cohorts. Over a median (interquartile range, IQR) follow-up period of 2 (1.16) years, $93.0 \%$ patients were men, with a mean age at presentation of $32( \pm 10)$ years. The four major routes of HIV transmission were homosexual contact (43.2\%), PWID (29.3\%), heterosexual contact (18.3\%), and bisexual contact (8.4\%). Overall, gbMSM (gay, bisexual, and homosexuals) accounted for $51.6 \%$ of the HIV population. HIV epidemics in the various HIV transmission route groups differed by cohort period: PWID percentages increased from 1.1 to $62.9 \%$ between periods 1 and 3 , and then declined to $5.3 \%$ in period 5 ; homosexual percentages declined to $19.7 \%$ in period 3 , and then increased to $67.6 \%$ in period 5. In total, $6210(27.4 \%)$ patients developed AIDS during five cohort periods; the lowest and the highest percentages were in period $3(17.7 \%)$ and in period 5 (35.9\%), respectively. Among the 6210 AIDS patients, 4571 (73.6\%) had developed at presentation; the lowest and highest numbers of cases were in period 3 (59.4\%) and period 1 (90.2\%), respectively. Among the 6210 patients, 1639 (26.4\%) developed AIDS during the follow-up period; the lowest and highest numbers of cases were in period $1(9.8 \%)$ and period $3(40.6 \%)$, respectively. 


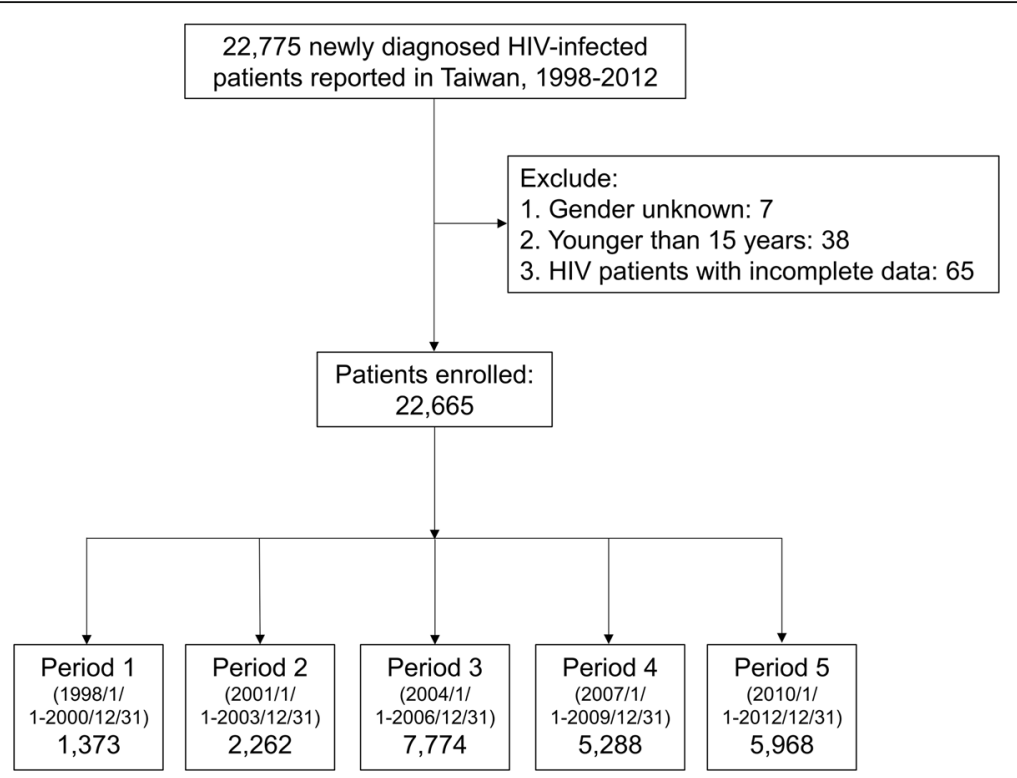

Fig. 1 Schematic illustration of the study population

AIDS incidence trends at presentation and during the follow-up period according to HIV-transmission route The probability of AIDS-free survival of various HIV-atrisk populations differed significantly throughout the five cohort periods (log-rank test, $P<0.001$ ) (Fig. 2). AIDS incidence trends at presentation and during follow-up over the five cohort periods differed by HIV-transmission route (Fig. 3a and b). AIDS incidence at presentation increased in the sexual contact groups $(P$ for trend $<0.001$ for homosexuals/heterosexuals; $P$ for trend $=0.648$ for bisexuals), whereas that in PWIDs declined to a nadir in period 3 and then increased slightly in period 5 ( $P$ for trend < 0.001) (Fig. 3a). AIDS incidence during the followup period increased from period 1 to a peak in periods 3 or 4 , and then declined slightly in period 5 in the sexual contact groups ( $P$ for trend $<0.001$ for homosexuals/heterosexuals; $P$ for trend $=0.549$ for bisexuals), whereas it increased throughout the five cohort periods in the PWIDs ( $P$ for trend $<0.001$ ) (Fig. 3b). Overall AIDS incidence at presentation and during the follow-up period was higher in the sexual contact population than in the PWIDs throughout the five cohort periods.

\section{Factors associated with AIDS incidence at presentation}

Table 2 lists the factors associated with AIDS incidence at presentation. Logistic regression analysis revealed the following risk factors associated with AIDS incidence at presentation: older age (31-40 years, $41-50$ years, and $\geq$ 51 years vs. $\leq 30$ years, all $P<0.001)$; male $(P<0.001)$; HIVtransmission route (bisexuals, heterosexuals, homosexuals, and other contacts vs. PWIDs, all $P<0.001$ ); cohort period (period 4 and period 5 vs. period 1 , all $P<0.001$ ); and region (all non-Taipei areas vs. Taipei area, all $P<0.01$ ). High income level (vs. low income level, $P<0.01$ ) and cohort Period 2 (vs. Period $1, P<0.001$ ) were factors that decreased AIDS incidence.

Factors associated with AIDS incidence during the followup period

Table 3 lists the factors associated with AIDS incidence during the follow-up period. On Cox regression analysis, the following factors were identified as risk factors associated with AIDS incidence during the follow-up period: older age (31-40 years, $41-50$ years, and $\geq 51$ years vs. $\leq 30$ years, all $P<0.01$ ); HIV-transmission route (bisexuals, heterosexuals, homosexuals, and other contact vs. PWIDs, all $P<0.001$ ); cohort period (periods $3-5$ vs. period 1, all $P<0.001$ ); northern Taiwan (vs. Taipei area, $P<0.001)$, CKD $(P<0.05)$; and HAART during the follow-up period $(P<0.001)$. High income level (vs. low income level, $P<0.05$ ) was protective factor.

\section{Discussion}

Although HAART has significantly altered the natural history of HIV infection in the cART era [1, 2], 27.4\% patients still developed AIDS during the cohort periods, with a majority (73.6\%) developing at HIV presentation. These findings indicate that in Taiwan, AIDS continues to pose a major threat to HIV patients, especially soon after diagnosis. Our study also revealed disparities in AIDS incidence trends in various HIV-at-risk populations. The disparities can be primarily explained by the different HIV-exposure-related sociodemographic factors and the influence of the adopted HIV prevention strategies; this 
Table 1 Sociodemographic, HIV-related variables, and comorbidities in patients newly diagnosed with HIV infection

\begin{tabular}{|c|c|c|c|c|c|c|c|}
\hline & \multirow{2}{*}{$\begin{array}{l}\text { Period } 1 \\
1 / 1 / 1998 \text { to } \\
12 / 31 / 2000 \\
(n=1373)\end{array}$} & \multirow{2}{*}{$\begin{array}{l}\text { Period } 2 \\
1 / 1 / 2001 \text { to } \\
12 / 31 / 2003 \\
(n=2262)\end{array}$} & \multirow{2}{*}{$\begin{array}{l}\text { Period } 3 \\
1 / 1 / 2004 \text { to } \\
12 / 31 / 2006 \\
(n=7774)\end{array}$} & \multirow{2}{*}{$\begin{array}{l}\text { Period } 4 \\
1 / 1 / 2007 \text { to } \\
12 / 31 / 2009 \\
(n=5288)\end{array}$} & \multirow{2}{*}{$\begin{array}{l}\text { Period } 5 \\
1 / 1 / 2010 \text { to } \\
12 / 31 / 2012 \\
(n=5968)\end{array}$} & \multirow{2}{*}{$\begin{array}{l}\text { Total } \\
(n=22,665)\end{array}$} & \multirow[t]{2}{*}{$P$-value } \\
\hline & & & & & & & \\
\hline Follow-up period, median (IQR; years) & $2(1.94)$ & $2(0.25)$ & $2(0)$ & $2(1.75)$ & $2(1.92)$ & $2(1.16)$ & $<0.001$ \\
\hline Age, mean (IQR; years) & $34.56(11.77)$ & $33.91(11.66)$ & $33.05(9.36)$ & $33.17(10.44)$ & $31.08(10.26)$ & $32.74(10.31)$ & $<0.001$ \\
\hline Age group, $n(\%)$ & & & & & & & $<0.001$ \\
\hline$\leq 30$ & $610(44.4)$ & $1058(46.8)$ & $3620(46.6)$ & $2530(47.8)$ & $3487(58.4)$ & $11,305(49.9)$ & \\
\hline $31-40$ & $445(32.4)$ & $723(32.0)$ & $2650(34.1)$ & $1606(30.4)$ & $1541(25.8)$ & $6965(30.7)$ & \\
\hline $41-50$ & $165(12.0)$ & $260(11.5)$ & $1113(14.3)$ & $800(15.1)$ & $624(10.5)$ & $2962(13.1)$ & \\
\hline$\geq 51$ & $153(11.1)$ & $221(9.8)$ & $391(5.0)$ & $352(6.7)$ & $316(5.3)$ & $1433(6.3)$ & \\
\hline Sex, n (\%) & & & & & & & $<0.001$ \\
\hline Female & $116(8.5)$ & $117(5.2)$ & $809(10.4)$ & $337(6.4)$ & $201(3.4)$ & $1580(7.0)$ & \\
\hline Male & $1257(91.5)$ & $2145(94.8)$ & 6965 (89.6) & 4951 (93.6) & 5767 (96.6) & $21,085(93.0)$ & \\
\hline Income level, $n$ (\%) & & & & & & & $<0.001$ \\
\hline Low & $805(58.6)$ & $1352(59.8)$ & $6147(79.1)$ & $2737(51.8)$ & $2744(46.0)$ & $13,785(60.8)$ & \\
\hline Intermediate & $411(29.9)$ & $585(25.8)$ & 1109 (14.3) & $1928(36.5)$ & $2388(40.0)$ & $6421(28.3)$ & \\
\hline High & $157(11.4)$ & $325(14.4)$ & $518(6.6)$ & $623(11.7)$ & $836(14.0)$ & $2459(10.9)$ & \\
\hline Urbanization, n (\%) & & & & & & & $<0.001$ \\
\hline Rural & $265(19.3)$ & $475(21.0)$ & $2933(37.7)$ & $1774(33.6)$ & $1937(32.5)$ & $7384(32.6)$ & \\
\hline Urban & $1108(80.7)$ & $1787(79.0)$ & $4841(62.3)$ & $3514(66.4)$ & $4031(67.5)$ & $15,281(67.4)$ & \\
\hline HIV-transmission route, $n$ (\%) & & & & & & & $<0.001$ \\
\hline Homosexual contact & $574(41.8)$ & $1125(49.7)$ & $1532(19.7)$ & $2516(47.6)$ & $4032(67.6)$ & $9779(43.2)$ & \\
\hline Heterosexual contact & $578(42.1)$ & $729(32.2)$ & $974(12.5)$ & $946(17.9)$ & $925(15.5)$ & $4152(18.3)$ & \\
\hline Bisexual contact & $197(14.4)$ & $278(12.3)$ & $338(4.4)$ & $453(8.6)$ & $632(10.6)$ & $1898(8.4)$ & \\
\hline PWID & $15(1.1)$ & $108(4.8)$ & $4887(62.9)$ & $1322(25.0)$ & $314(5.3)$ & $6646(29.3)$ & \\
\hline Other ${ }^{a}$ & $9(0.6)$ & $22(1.0)$ & $43(0.5)$ & $51(1.0)$ & $65(1.1)$ & $190(0.8)$ & \\
\hline \multicolumn{8}{|l|}{ Comorbidities, n (\%) } \\
\hline DM & $16(1.2)$ & $60(2.7)$ & $193(2.5)$ & $144(2.7)$ & $155(2.6)$ & $568(2.5)$ & $<0.05$ \\
\hline CKD & $13(1.0)$ & $25(1.1)$ & $94(1.2)$ & $84(1.6)$ & $91(1.5)$ & $307(1.4)$ & 0.114 \\
\hline $\mathrm{CHF}$ & $4(0.3)$ & $9(0.4)$ & $23(0.3)$ & $30(0.6)$ & $26(0.4)$ & $92(0.4)$ & 0.177 \\
\hline COPD & $24(1.8)$ & $74(3.3)$ & $173(2.2)$ & $128(2.4)$ & $108(1.8)$ & $507(2.2)$ & $<0.05$ \\
\hline Cancer & $44(3.2)$ & $129(5.7)$ & $439(5.7)$ & $451(8.5)$ & $583(9.8)$ & $1646(7.3)$ & $<0.001$ \\
\hline CVD & $12(0.9)$ & $31(1.4)$ & $83(1.1)$ & $74(1.4)$ & $57(1.0)$ & $257(1.1)$ & 0.121 \\
\hline HAART in each cohort period, $n(\%)$ & $605(44.1)$ & $1273(56.3)$ & $1546(19.9)$ & $1237(23.4)$ & $2345(39.3)$ & $7006(30.9)$ & $<0.001$ \\
\hline AIDS incidence in each cohort period, $n$ (\%) & $438(31.9)$ & $519(22.9)$ & $1378(17.7)$ & $1732(32.8)$ & $2143(35.9)$ & $6210(27.4)$ & $<0.001$ \\
\hline AIDS incidence at presentation, $n(\%)$ & $395(90.2)$ & $451(86.9)$ & $819(59.4)$ & $1274(73.6)$ & $1632(76.2)$ & $4571(73.6)$ & $<0.001$ \\
\hline $\begin{array}{l}\text { AIDS incidence during the follow-up } \\
\text { period, } n(\%)\end{array}$ & $43(9.8)$ & $68(13.1)$ & $559(40.6)$ & $458(26.4)$ & $511(23.8)$ & $1639(26.4)$ & $<0.001$ \\
\hline HIV diagnosis region, $n$ (\%) & & & & & & & $<0.001$ \\
\hline Taipei area & $622(45.3)$ & $1061(46.9)$ & $2266(29.2)$ & $1923(36.4)$ & $2027(34.0)$ & 7899 (34.9) & \\
\hline Northern Taiwan & $161(11.7)$ & $262(11.6)$ & $1278(16.4)$ & $661(12.5)$ & $850(14.2)$ & $3212(14.2)$ & \\
\hline
\end{tabular}


Table 1 Sociodemographic, HIV-related variables, and comorbidities in patients newly diagnosed with HIV infection (Continued)

\begin{tabular}{|c|c|c|c|c|c|c|c|}
\hline & \multirow{2}{*}{$\begin{array}{l}\text { Period } 1 \\
1 / 1 / 1998 \text { to } \\
12 / 31 / 2000 \\
(n=1373)\end{array}$} & \multirow{2}{*}{$\begin{array}{l}\text { Period } 2 \\
1 / 1 / 2001 \text { to } \\
12 / 31 / 2003 \\
(n=2262)\end{array}$} & \multirow{2}{*}{$\begin{array}{l}\text { Period } 3 \\
1 / 1 / 2004 \text { to } \\
12 / 31 / 2006 \\
(n=7774)\end{array}$} & \multirow{2}{*}{$\begin{array}{l}\text { Period } 4 \\
1 / 1 / 2007 \text { to } \\
12 / 31 / 2009 \\
(n=5288)\end{array}$} & \multirow{2}{*}{$\begin{array}{l}\text { Period } 5 \\
1 / 1 / 2010 \text { to } \\
12 / 31 / 2012 \\
(n=5968)\end{array}$} & \multirow{2}{*}{$\begin{array}{l}\text { Total } \\
(n=22,665)\end{array}$} & \multirow[t]{2}{*}{$P$-value } \\
\hline & & & & & & & \\
\hline Central Taiwan & $238(17.3)$ & $339(15.0)$ & 1539 (19.8) & $913(17.3)$ & $1052(17.6)$ & $4081(18.0)$ & \\
\hline Southern Taiwan & $12(0.9)$ & $244(10.8)$ & 1057 (13.6) & $593(11.2)$ & $669(11.2)$ & 2687 (11.9) & \\
\hline Kaoping area & $192(14.0)$ & 307 (13.6) & 1535 (19.8) & $1086(20.5)$ & $1191(20.0)$ & $4311(19.0)$ & \\
\hline Eastern Taiwan & $36(2.6)$ & $49(2.2)$ & $99(1.3)$ & $112(2.1)$ & $179(3.0)$ & $475(2.1)$ & \\
\hline
\end{tabular}

Abbreviations: AIDS acquired immunodeficiency syndrome, COPD chronic obstructive pulmonary disease, CHF chronic heart failure, CKD chronic kidney disease, CVD cardiovascular disease, DM diabetes mellitus, HAART highly active antiretroviral therapy, IQR interquartile range, $P W I D$ people who injected drugs, SD standard deviation

ancludes those exposed to blood products, mother-to-child transmission, and unknown exposures

knowledge will help prioritize resource reallocation for HIV diagnosis and the HIV-care continuum according to various targeted populations (Table 1, Fig. 3). The HIV epidemic in Taiwan is similar to that in other countries of the Asia-Pacific and North American regions [3, 4, 20, 21], where gbMSM are the predominant HIV transmission groups, and AIDS at presentation remains common. Therefore, this Taiwanese study's findings should be of interest globally.

The late presentation (LP) of HIV is detrimental at both the individual [5-8] and general population levels $[9,10]$. Different definitions have been adopted to indicate the LP of HIV, such as "a CD4 cell count of $<350$ cells $/ \mu \mathrm{L}$ or AIDS-defining event at the first follow-up [3]" or "a CD4 cell count of $<200$ cells $/ \mu \mathrm{L}$ or an AIDSdefining event within 3 months of HIV diagnosis [4]". The lack of a standardized definition of LP makes it difficult to draw precise comparisons of the prevalence data reported from different studies. After using "a CD4 cell count of $<200$ cells $/ \mu \mathrm{L}$ or AIDS incidence in $\leq 3$ months of HIV diagnosis" as a definition of LP (i.e., as the definition of AIDS incidence at presentation in the present study), the present study found a lower proportion of HIV patients with LP (20.2\%) than that reported from other Asia-Pacific countries in the TREAT Asia HIV Observational Database (TAHOD) (72\%) [4], China (27. 3\%) [3], and European countries [COHERE (33.2\%)] [5]. The lower prevalence of LP in the present study compared with that in TAHOD may be attributable to a nationwide program of free anonymous VCT adopted in Taiwan since 1997 and enrollment of low-income countries in TAHOD, which is limited to health care access and health literacy. Even though the overall LP prevalence in Taiwan seems to be lower than that in other countries, HIV prevention and care in various HIV transmission groups remains a problem in Taiwan.

Similar to worldwide trends $[3,4,20,21]$, our study revealed that gbMSM has been emerging as the predominant HIV-transmission route, accounting for $78.2 \%$ new-
HIV-infection cases in period 5. Furthermore, the trend of increasing LP among gbMSM in Taiwan showed no obvious signs of decline/reversal (Fig. 3). Therefore, reduction in the HIV epidemic and LP in gbMSM should be prioritized in Taiwan's HIV prevention strategies. TCDC has adopted a wide range of HIV prevention programs among HIV-at-risk populations, especially the gbMSM population. A nationwide program of free anonymous VCT through a clinical service delivery model was initiated at several hospitals, community health centers, and nongovernmental organizations in 1997. The number of visitors who received VCT has increased steadily, and the percentage of new-HIV-infection cases through VCT increased from $9.0 \%$ in 2004 to $30.0 \%$ in 2010, after which it has plateaued [22]. In addition, TCDC also established gbMSM community health centers, employed services of online opinion leaders, and promoted VCT outreach services at saunas and pubs. Even though gbMSM have access to a broad range of free HIV services and organized community structures in Taiwan, the rising trend of LP in the gbMSM population indicates that HIV-at-risk gbMSM have been unaware/unwilling to receive HIV testing until late stages of HIV. Therefore, an integrated approach should be urgently employed to overcome HIV testing barriers in high-prevalence areas. These barriers include redressal of low risk perception [23], stigma and fear of discrimination [24], concerns about confidentiality [25], and possible structural barriers that contribute to poor HIV testing access in areas other than Taipei and among lowincome population groups (Table 2). Taipei is the capital of Taiwan and has ample resources for HIV prevention and treatment [26].

Our study revealed that heterosexual contact is the second most common HIV-transmission route in Taiwan, accounting for $15.5 \%$ new-HIV-infection cases in period 5 . Although the contribution of heterosexuals for HIV transmission is lower than that of gbMSMs, the findings reveal significantly higher LP prevalence among heterosexuals 

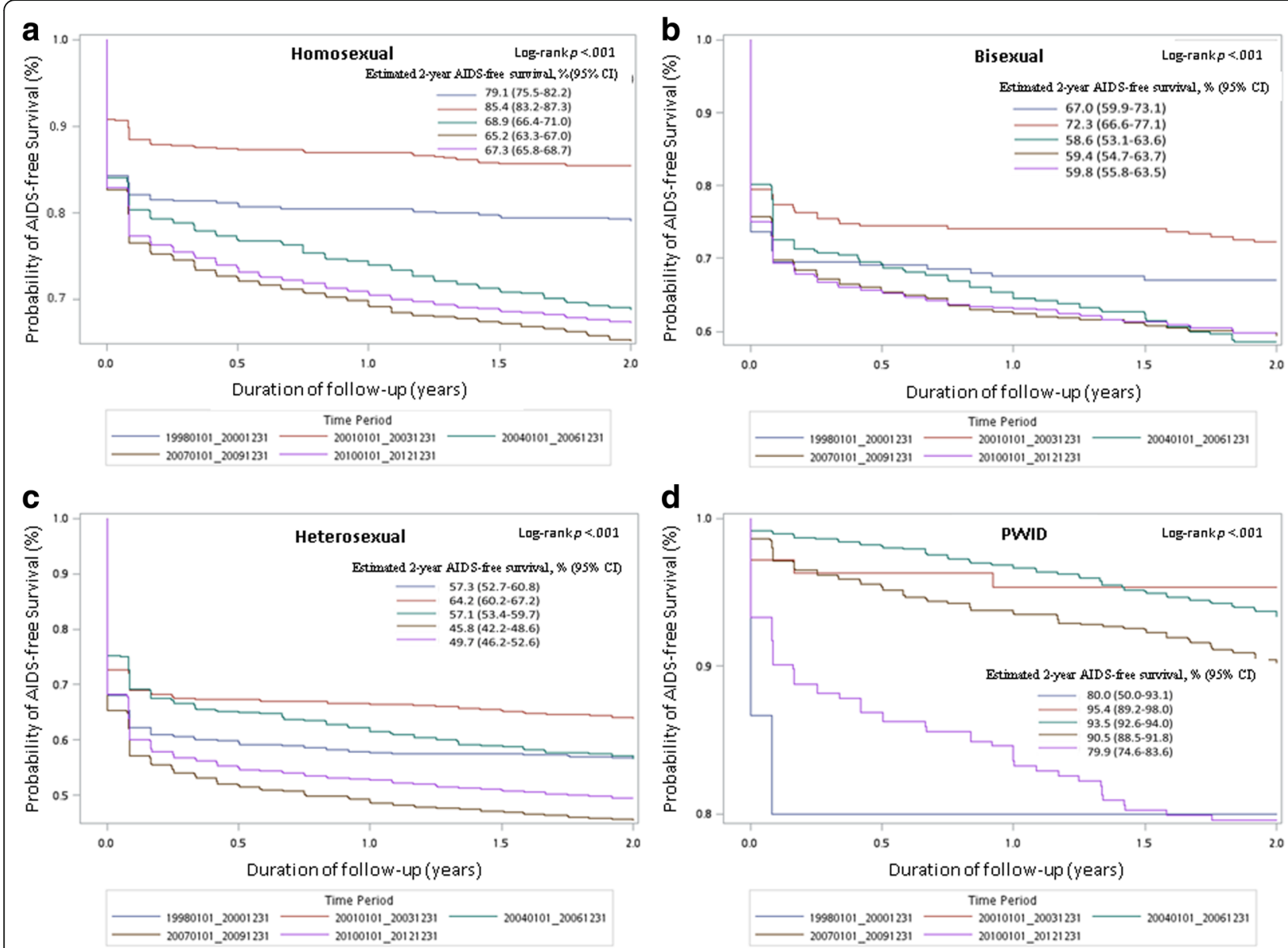

Fig. 2 AIDS-free survival analysis stratified by five cohort periods in a homosexual, b bisexual, c heterosexual, and $\mathbf{d}$ PWID populations

than in gbMSMs [adjusted OR (95\% CI), 1.54 (1.40-1.70)] and an upward trend of LP among heterosexuals ( $P$ for trend $<0.001)$; this warrants a critical rethink of the HIV prevention strategies for both heterosexuals and gbMSMs in Taiwan. The finding of higher LP prevalence among heterosexuals in the present study is consistent with findings from other studies [5, 27], and may be attributable to the lower HIV testing rates among heterosexuals [28]. One explanation for this is the particular history of the HIV epidemic in Taiwan. Because HIV transmission in Taiwan has occurred predominantly within gbMSMs since 2008, HIV prevention and HIV-education strategies have long been shaped around gbMSMs. HIV prevention campaigns aimed at heterosexuals have either been lacking or were subsumed within the broader prevention campaigns focused primarily on other sexually transmitted infections. Other explanations include a lower risk perception and concerns regarding confidentiality $[4,29]$. In addition, the rapid network and community-driven response to HIV prevention strategies among gbMSMs is not readily transferable to heterosexuals because of the wide diversity of sociodemographic variables (i.e., polyamory and commercial sex workers) of the HIV epidemic among the heterosexuals [20,30]. Therefore, implementation of evidence-based population-specific prevention strategies is critical for achieving early HIV diagnosis in heterosexuals. In 2016, TCDC launched a program to distribute HIV home-based and self-testing kits to nongovernmental organizations, health stations, and to heterosexual and gbMSM communities. The high uptake and acceptance of these strategies among heterosexuals holds promise for increasing the uptake of HIV testing services among heterosexuals [31].

Taiwan experienced a major HIV epidemic among PWIDs during 2003-2008, and then a substantial reduction in HIV infection in PWIDs because TCDC launched harm-reduction programs in August 2005 [14]. Consequently, only 3.2\% (77/2406) of new-HIV-infection cases were attributed to PWIDs in Taiwan in 2016 [14, 32]. In contrast to some Asian and European studies [4, 5], PWIDs were not identified as a major LP risk group in our study (Table 2). A possible cause of the discrepancy may be the predominance of the HIV CRF07_BC strain 


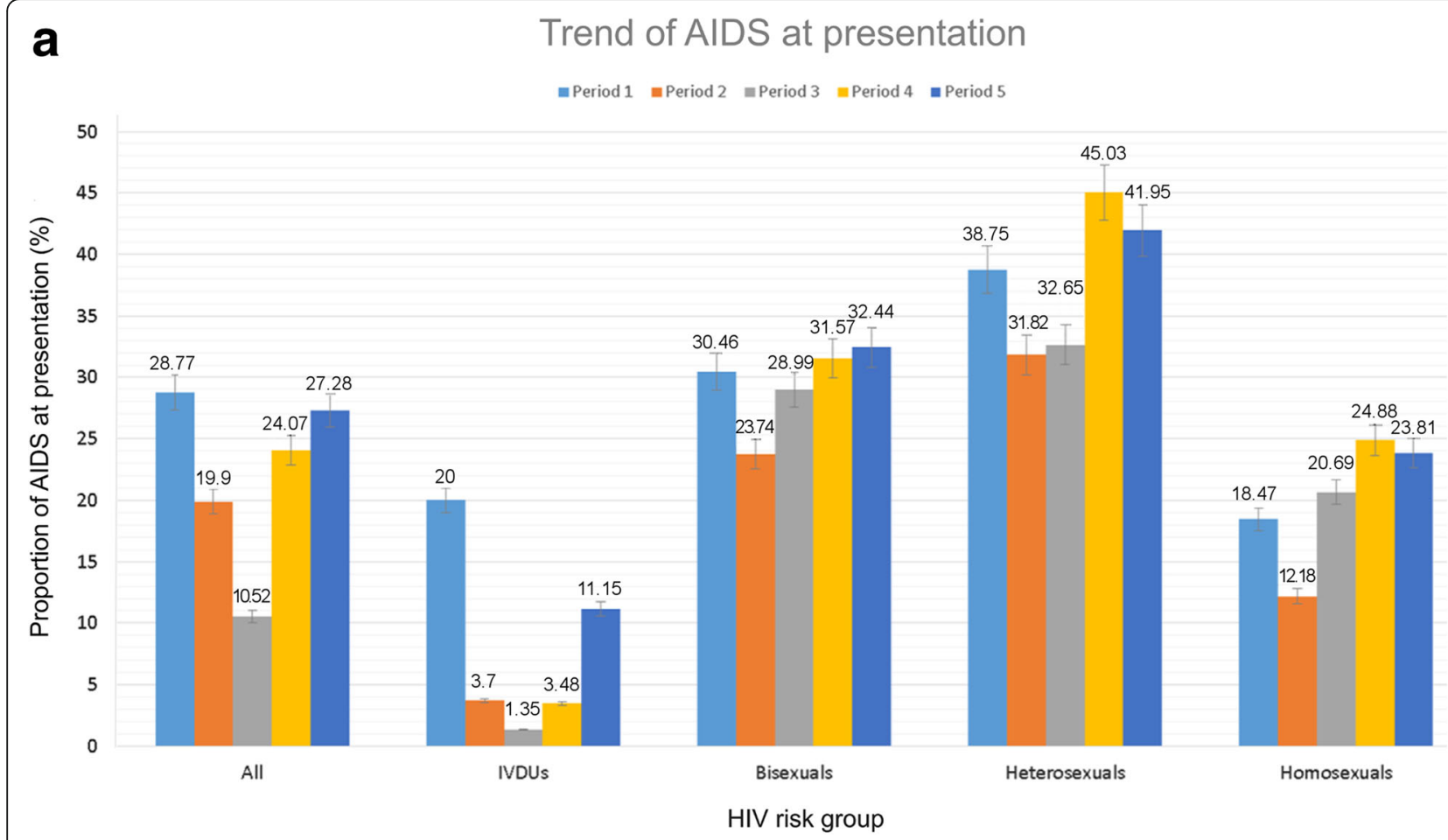

\section{b Trend of AIDS during observation period}

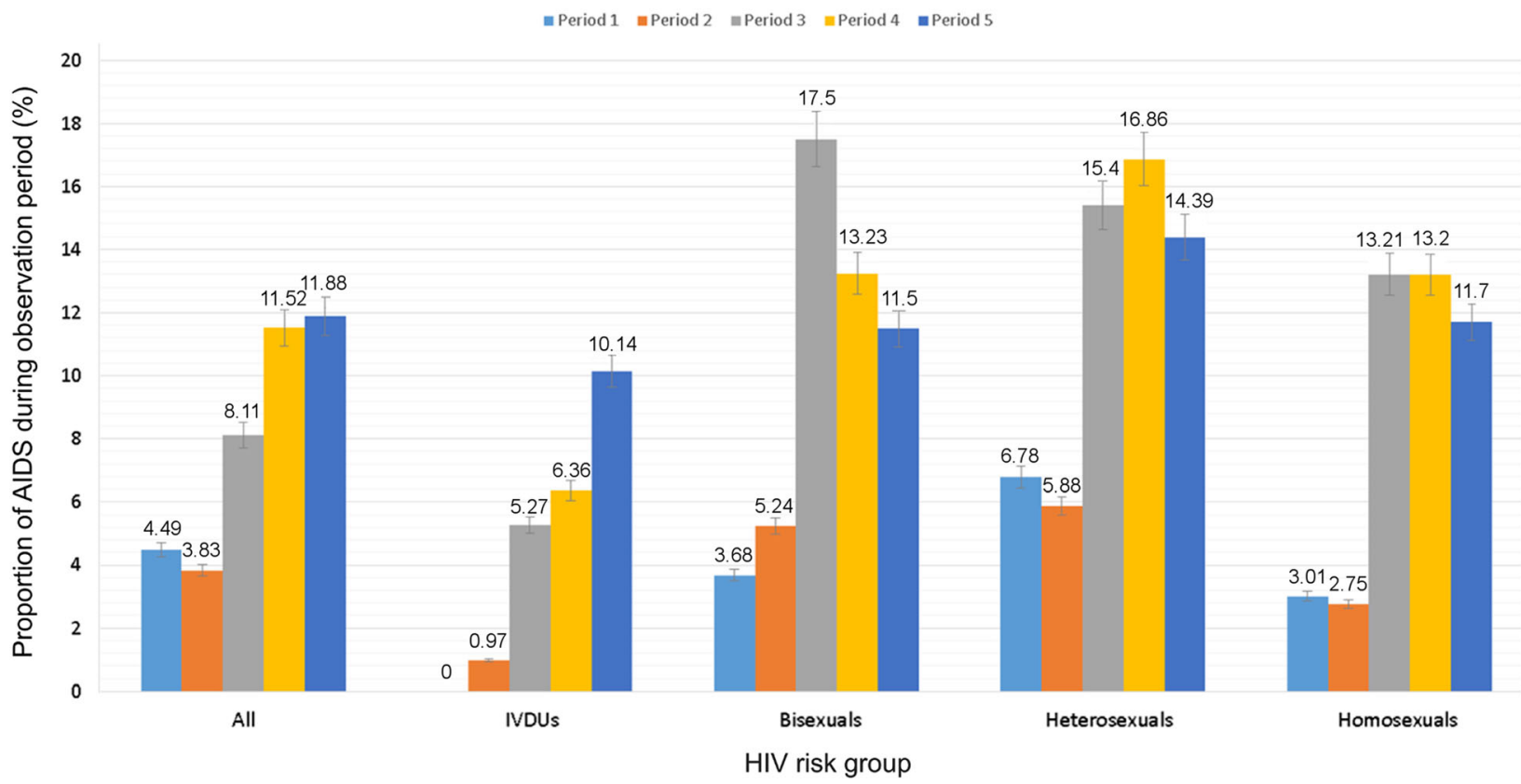

Fig. 3 AIDS-incidence trends at presentation (a) and during the follow-up period (b) in HIV-transmission-route groups. a Overall, AIDS incidence at presentation declined from $28.8 \%$ in period 1 to a nadir of $10.5 \%$ in period 3 and then increased to $27.3 \%$ in period 5 . After stratification by HIV-transmission route, however, AIDS incidence at presentation increased throughout the five cohort periods in the heterosexual ( $P$ for trend $<0.001$ ), homosexual ( $P$ for trend $<0.001$ ), and bisexual risk groups ( $P$ for trend $=0.648$ ), whereas decreased to a nadir in period 3 and then increased to a peak in period 5 in in the PWID groups ( $P$ for trend $<0.001$ ). b AIDS incidence during the follow-up period increased from $4.5 \%$ in period 1 to $11.9 \%$ in period 5 . After stratification by HIV-transmission route, AIDS incidence during the follow-up period increased from period 1 to a peak in periods 3 and 4 and then declined in period 5 in heterosexual ( $P$ for trend $<0.001$ ), homosexual $(P$ for trend $<0.001)$, and bisexual risk groups ( $P$ for trend $=0.549$ ), whereas in PWIDs it increased throughout the five cohort periods $(P$ for trend $<0.001)$ 
Table 2 Risk factors for AIDS incidence at presentation among patients newly diagnosed with HIV infection

\begin{tabular}{|c|c|c|c|c|c|}
\hline & Number of patients, $n$ & Number of AIDS, $n$ & $\%$ & $\begin{array}{l}\text { Univariable analysis, } \\
\text { crude OR }(95 \% \mathrm{Cl})\end{array}$ & $\begin{array}{l}\text { Multivariable analysis, } \\
\text { adjusted OR ( } 95 \% \mathrm{Cl})\end{array}$ \\
\hline \multicolumn{6}{|l|}{ Age group } \\
\hline$\leq 30$ & 11,305 & 1445 & 12.8 & 1.0 (Reference) & 1.0 (Reference) \\
\hline $31-40$ & 6965 & 1594 & 22.9 & $2.03(1.87-2.19)^{* * *}$ & $2.76(2.53-3.01)^{* * *}$ \\
\hline $41-50$ & 2962 & 886 & 29.9 & $2.91(2.65-3.21)^{* * *}$ & $4.19(3.74-4.69)^{* * *}$ \\
\hline$\geq 51$ & 1433 & 646 & 45.1 & $5.60(4.98-6.30)^{* * *}$ & $4.64(4.00-5.37)^{* * *}$ \\
\hline \multicolumn{6}{|l|}{ Sex } \\
\hline Female & 1580 & 257 & 16.3 & 1.0 (Reference) & 1.0 (Reference) \\
\hline Male & 21,085 & 4314 & 20.5 & $1.32(1.15-1.52)^{* * *}$ & $1.39(1.17-1.65)^{* * *}$ \\
\hline \multicolumn{6}{|l|}{ HIV-transmission route } \\
\hline PWID & 6646 & 154 & 2.3 & 1.0 (Reference) & 1.0 (Reference) \\
\hline Bisexual contact & 1898 & 572 & 30.1 & $18.19(15.08-21.93)^{* * *}$ & $20.28(16.59-24.79)^{* * *}$ \\
\hline Heterosexual contact & 4152 & 1592 & 38.3 & $26.22(22.08-31.12)^{* * *}$ & $24.48(20.39-29.39)^{* * *}$ \\
\hline Homosexual contact & 9779 & 2147 & 22.0 & $11.86(10.04-14.01)^{* * *}$ & $16.02(13.35-19.22)^{* * *}$ \\
\hline Other $^{a}$ & 190 & 106 & 55.8 & $53.19(38.33-73.84)^{* * *}$ & $38.23(26.94-54.24)^{* * *}$ \\
\hline \multicolumn{6}{|l|}{ Urbanization } \\
\hline Rural & 7384 & 1288 & 17.4 & 1.0 (Reference) & 1.0 (Reference) \\
\hline Urban & 15,281 & 3283 & 21.5 & $1.30(1.21-1.39)^{* * *}$ & $0.96(0.88-1.05)$ \\
\hline \multicolumn{6}{|l|}{ Income level, $n$ (\%) } \\
\hline Low & 13,785 & 2328 & 16.9 & 1.0 (Reference) & 1.0 (Reference) \\
\hline Intermediate & 6421 & 1546 & 24.1 & $1.56(1.45-1.68)^{* * *}$ & $0.99(0.91-1.07)$ \\
\hline High & 2459 & 697 & 28.3 & $1.95(1.76-2.15)^{* * *}$ & $0.85(0.76-0.94)^{* *}$ \\
\hline \multicolumn{6}{|l|}{ Cohort period } \\
\hline Period 1 & 1373 & 395 & 28.8 & 1.0 (Reference) & 1.0 (Reference) \\
\hline Period 2 & 2262 & 451 & 19.9 & $0.62(0.53-0.72)^{* * *}$ & $0.65(0.55-0.77)^{* * *}$ \\
\hline Period 3 & 7774 & 819 & 10.5 & $0.29(0.25-0.34)^{* * *}$ & $0.87(0.75-1.01)$ \\
\hline Period 4 & 5288 & 1274 & 24.1 & $0.79(0.69-0.90)^{* * *}$ & $1.32(1.15-1.53)^{* * *}$ \\
\hline Period 5 & 5968 & 1632 & 27.4 & $0.93(0.82-1.06)$ & $1.33(1.15-1.53)^{* * *}$ \\
\hline \multicolumn{6}{|l|}{ HIV-diagnosis region } \\
\hline Taipei area & 7899 & 1656 & 21.0 & 1.0 (Reference) & 1.0 (Reference) \\
\hline Northern Taiwan & 3212 & 608 & 18.9 & $0.88(0.80-0.98)^{*}$ & $1.17(1.05-1.32)^{* *}$ \\
\hline Central Taiwan & 4081 & 839 & 20.6 & $0.98(0.89-1.07)$ & $1.25(1.13-1.39)^{* * *}$ \\
\hline Southern Taiwan & 2687 & 525 & 19.5 & $0.92(0.82-1.02)$ & $1.26(1.11-1.42)^{* * *}$ \\
\hline Kaoping area & 4311 & 817 & 19.0 & $0.88(0.80-0.97)^{* *}$ & $1.18(1.06-1.32)^{* *}$ \\
\hline Eastern Taiwan & 475 & 126 & 26.5 & $1.36(1.10-1.69)^{* *}$ & $1.27(1.00-1.62)^{* *}$ \\
\hline \multicolumn{6}{|l|}{ DM } \\
\hline No & 22,097 & 4362 & 19.7 & 1.0 (Reference) & 1.0 (Reference) \\
\hline Yes & 568 & 202 & 35.6 & $2.26(1.90-2.69)^{* * *}$ & $1.04(0.84-1.29)$ \\
\hline \multicolumn{6}{|l|}{ CKD } \\
\hline No & 22,358 & 4456 & 19.9 & 1.0 (Reference) & 1.0 (Reference) \\
\hline Yes & 307 & 108 & 35.2 & $2.18(1.72-2.76)^{* * *}$ & $1.28(0.96-1.71)$ \\
\hline \multicolumn{6}{|l|}{$\mathrm{CHF}$} \\
\hline No & 22,573 & 4522 & 20.0 & 1.0 (Reference) & 1.0 (Reference) \\
\hline Yes & 92 & 42 & 45.7 & $3.50(2.32-5.27)^{* * *}$ & $1.41(0.85-2.36)$ \\
\hline
\end{tabular}


Table 2 Risk factors for AIDS incidence at presentation among patients newly diagnosed with HIV infection (Continued)

\begin{tabular}{|c|c|c|c|c|c|}
\hline & Number of patients, $n$ & Number of AIDS, $n$ & $\%$ & $\begin{array}{l}\text { Univariable analysis, } \\
\text { crude OR ( } 95 \% \mathrm{Cl})\end{array}$ & $\begin{array}{l}\text { Multivariable analysis, } \\
\text { adjusted OR ( } 95 \% \mathrm{Cl})\end{array}$ \\
\hline \multicolumn{6}{|l|}{ COPD } \\
\hline No & 22,158 & 4522 & 19.6 & 1.0 (Reference) & 1.0 (Reference) \\
\hline Yes & 507 & 220 & 43.4 & $3.14(2.62-3.75)^{* * *}$ & $1.63(1.32-2.01)^{* * *}$ \\
\hline \multicolumn{6}{|l|}{ Cancer } \\
\hline No & 21,019 & 4061 & 19.3 & 1.0 (Reference) & 1.0 (Reference) \\
\hline Yes & 1646 & 503 & 30.6 & $1.85(1.65-2.06)^{* * *}$ & $1.15(1.02-1.30)^{*}$ \\
\hline \multicolumn{6}{|l|}{ CVD } \\
\hline No & 22,408 & 4459 & 19.9 & 1.0 (Reference) & 1.0 (Reference) \\
\hline Yes & 257 & 105 & 40.9 & $2.82(2.20-3.62)^{* * *}$ & $1.33(0.97-1.82)$ \\
\hline
\end{tabular}

Note. ${ }^{*} P<0.05 ;{ }^{* *} P<0.01 ; * * * 0.001$

Abbreviation: AIDS acquired immunodeficiency syndrome; $C H F$ chronic heart failure; $C l$ confidence intervals; $C K D$ chronic kidney disease; $C O P D$ chronic obstructive pulmonary disease; CVD cardiovascular disease; DM diabetes mellitus; OR odd ratios; PWID people who injected drugs

ancludes those exposed to blood products, mother-to-child transmission, and unknown exposures

among PWIDs in Taiwan, which is characterized by slow immunological progression [33, 34]; another reason could be the legal implementation of an active surveillance for prison inmates since 1991 with resultant early diagnoses of HIV in PWIDs [15, 35].

Consistent with relevant studies, the present study also identified old age as an LP risk factor [4, 36] (Table 2). These results are likely attributable to changes in riskrelated behavior (i.e., decreased condom use) and lower HIV-risk perception among older people, which resulted in a higher proportion of diagnosis during hospitalization [37]. Moreover, primary physicians may not consider the possibility of HIV infection among the older population because of masking by multiple comorbidities [38], variations in HIV symptom manifestation [39], and underestimation of HIV-risk transmission behaviors [40]. Effective HIV prevention education for early HIV diagnosis in older populations rests in part on countering the misconceptions about HIV transmission risk and on enhancing the awareness of healthcare providers.

Mathematical models suggest that universal HIV testing followed by immediate treatment can decrease HIV incidence at the population level [41]. Although active surveillance programs among specific populations in Taiwan have been consecutively adopted since 1988, anonymous VCT has been a strategic priority for HIV testing among the sexual contact population since 1997. However, testing according to the perceived HIV transmission risk and willingness to undergo HIV testing among the sexual contact population likely contributes to the increasing LP prevalence in HIV-at-risk populations (Fig. 3a). HIV-screening implementation as part of routine care or implementation of opt-out testing in both healthcare and nonhealthcare settings may help increase HIV testing rates, destigmatize it, and improve healthcare access for new-HIV-infection cases [42, 43]. However, routine HIV-screening approaches in HIV-atrisk populations without permission, except in specific situations, are prohibited by law in Taiwan. Therefore, an integrated approach to scale-up current VCT strategies tailored to HIV-at-risk populations is urgently required to increase HIV testing coverage among the sexual contact and older populations and among those who reside outside of the Taipei area (Table 2). This integrated approach should include education to increase HIV-risk perception, eliminate stigma and discrimination, and adopt a flexible approach to HIV testing, including peer-based [44] or home-based HIV testing services [31], and indicator-guided HIV testing by healthcare providers $[45,46]$.

Another valuable finding of the present study is the disparity in AIDS incidence trends during the follow-up period among the various HIV-at-risk populations in the five cohort periods (Fig. 3). The higher AIDS prevalence during follow-up in the sexual contact population than among PWIDs in Taiwan may be attributable to the higher LP prevalence in the sexual contact population (Table 2) which may result from low risk perception, stigma and discrimination, concerns about confidentiality, and uneven distribution of resource for HIV prevention as mentioned above, and be intrinsically linked to HIV-1 genetic diversity in Taiwan. Serotype B is the predominant strain in the sexual contact groups, whereas CRF_07 BC is the major strain in PWIDs [33], which is characterized by slower immunological progression compared with those in serotype B [33, 34]. Several crucial strategies have been implemented to increase the HIV-care continuum in Taiwan, including access to free HAART since 1997, initiation of HAART at higher CD4count thresholds $\left(\mathrm{CD} 4<200\right.$ cells $/ \mathrm{mm}^{3}$ in $2006,<350$ 
Table 3 Risk factors for AIDS incidence during the follow-up among patients newly diagnosed with HIV infection

\begin{tabular}{|c|c|c|c|c|c|}
\hline & $\begin{array}{l}\text { Number of } \\
\text { patients, } n\end{array}$ & $\begin{array}{l}\text { Number of } \\
\text { AIDS, } n\end{array}$ & $\%$ & $\begin{array}{l}\text { Univariable analysis, } \\
\text { crude HR }(95 \% \mathrm{Cl})\end{array}$ & $\begin{array}{l}\text { Multivariable analysis } \\
\text { adjusted HR (95\% Cl) }\end{array}$ \\
\hline \multicolumn{6}{|l|}{ Age group } \\
\hline$\leq 30$ & 9826 & 843 & 8.6 & 1.0 (Reference) & 1.0 (Reference) \\
\hline $31-40$ & 5312 & 442 & 8.3 & $0.97(0.87-1.09)$ & $1.17(1.04-1.32)^{* *}$ \\
\hline $41-50$ & 2028 & 227 & 11.2 & $1.35(1.16-1.56)^{* * *}$ & $1.68(1.44-1.96)^{* * *}$ \\
\hline$\geq 51$ & 737 & 127 & 17.2 & $2.19(1.82-2.64)^{* * *}$ & $2.36(1.90-2.92)^{* * *}$ \\
\hline \multicolumn{6}{|l|}{ Sex } \\
\hline Female & 1302 & 96 & 7.4 & 1.0 (Reference) & 1.0 (Reference) \\
\hline Male & 16,601 & 1543 & 9.3 & $1.26(1.03-1.55)^{*}$ & $1.16(0.93-1.44)$ \\
\hline \multicolumn{6}{|l|}{ HIV-transmission route } \\
\hline PWID & 6435 & 361 & 5.6 & 1.0 (Reference) & 1.0 (Reference) \\
\hline Bisexual contact & 1322 & 148 & 11.2 & $2.05(1.69-2.48)^{* * *}$ & $2.62(2.11-3.24)^{* * *}$ \\
\hline Heterosexual contact & 2496 & 312 & 12.5 & $2.33(2.00-2.71)^{* * *}$ & $2.79(2.35-3.31)^{* * *}$ \\
\hline Homosexual contact & 7602 & 808 & 10.6 & $1.94(1.71-2.19)^{* * *}$ & $2.58(2.19-3.03)^{* * *}$ \\
\hline Other $^{\mathrm{a}}$ & 48 & 10 & 20.8 & $4.92(2.62-9.22)^{* * *}$ & $4.90(2.58-9.31)^{* * *}$ \\
\hline \multicolumn{6}{|l|}{ Urbanization } \\
\hline Rural & 6038 & 557 & 9.2 & 1.0 (Reference) & 1.0 (Reference) \\
\hline Urban & 11,865 & 1082 & 9.1 & $0.99(0.89-1.09)$ & $0.93(0.83-1.04)$ \\
\hline \multicolumn{6}{|l|}{ Income level, n (\%) } \\
\hline Low & 11,323 & 950 & 8.4 & 1.0 (Reference) & 1.0 (Reference) \\
\hline Intermediate & 4833 & 508 & 10.5 & $1.26(1.13-1.41)^{* * *}$ & $0.97(0.86-1.08)$ \\
\hline High & 1747 & 181 & 10.4 & $1.24(1.06-1.46)^{* *}$ & $0.84(0.71-0.99)^{*}$ \\
\hline \multicolumn{6}{|l|}{ Cohort period } \\
\hline Period 1 & 957 & 43 & 4.5 & 1.0 (Reference) & 1.0 (Reference) \\
\hline Period 2 & 1777 & 68 & 3.8 & $0.85(0.58-1.24)$ & $0.82(0.56-1.21)$ \\
\hline Period 3 & 6890 & 559 & 8.1 & $1.84(1.35-2.51)^{* * *}$ & $3.32(2.42-4.56)^{* * *}$ \\
\hline Period 4 & 3976 & 458 & 11.5 & $2.67(1.95-3.65)^{* * *}$ & $3.53(2.57-4.84)^{* * *}$ \\
\hline Period 5 & 4303 & 511 & 11.9 & $2.76(2.02-3.76)^{* * *}$ & $3.04(2.22-4.17)^{* * * *}$ \\
\hline \multicolumn{6}{|l|}{ Region } \\
\hline Taipei area & 6166 & 526 & 8.5 & 1.0 (Reference) & 1.0 (Reference) \\
\hline Northern Taiwan & 2581 & 279 & 10.8 & $1.28(1.11-1.48)^{* * *}$ & $1.41(1.22-1.64)^{* * *}$ \\
\hline Central Taiwan & 3209 & 275 & 8.6 & $1.00(0.87-1.16)$ & $1.06(0.91-1.23)$ \\
\hline Southern Taiwan & 2137 & 197 & 9.2 & $1.09(0.92-1.28)$ & $1.17(0.98-1.38)$ \\
\hline Kaoping area & 3466 & 324 & 9.4 & $1.10(0.96-1.27)$ & $1.14(0.98-1.32)$ \\
\hline Eastern Taiwan & 344 & 38 & 11.1 & $1.30(0.94-1.81)$ & $1.16(0.82-1.64)$ \\
\hline \multicolumn{6}{|l|}{ DM } \\
\hline No & 17,556 & 1590 & 9.1 & 1.0 (Reference) & 1.0 (Reference) \\
\hline Yes & 347 & 49 & 14.1 & $1.69(1.27-2.25)^{* * * *}$ & $1.08(0.79-1.46)$ \\
\hline \multicolumn{6}{|l|}{ CKD } \\
\hline No & 17,717 & 1610 & 9.1 & 1.0 (Reference) & 1.0 (Reference) \\
\hline Yes & 186 & 29 & 15.6 & $1.89(1.31-2.73)^{* * *}$ & $1.49(1.02-2.17)^{*}$ \\
\hline \multicolumn{6}{|l|}{$\mathrm{CHF}$} \\
\hline No & 17,861 & 1630 & 9.1 & 1.0 (Reference) & 1.0 (Reference) \\
\hline Yes & 42 & 9 & 21.4 & $2.82(1.46-5.43)^{* *}$ & $1.81(0.92-3.58)$ \\
\hline
\end{tabular}


Table 3 Risk factors for AIDS incidence during the follow-up among patients newly diagnosed with HIV infection (Continued)

\begin{tabular}{|c|c|c|c|c|c|}
\hline & $\begin{array}{l}\text { Number of } \\
\text { patients, } n\end{array}$ & $\begin{array}{l}\text { Number of } \\
\text { AIDS, } n\end{array}$ & $\%$ & $\begin{array}{l}\text { Univariable analysis, } \\
\text { crude HR }(95 \% \mathrm{Cl})\end{array}$ & $\begin{array}{l}\text { Multivariable analysis, } \\
\text { adjusted HR }(95 \% \mathrm{CI})\end{array}$ \\
\hline \multicolumn{6}{|l|}{ COPD } \\
\hline No & 17,626 & 1604 & 9.1 & 1.0 (Reference) & 1.0 (Reference) \\
\hline Yes & 277 & 35 & 12.6 & $1.47(1.05-2.05)^{*}$ & $1.00(0.71-1.41)$ \\
\hline \multicolumn{6}{|l|}{ Cancer } \\
\hline No & 16,788 & 1506 & 9.0 & 1.0 (Reference) & 1.0 (Reference) \\
\hline Yes & 1115 & 133 & 11.9 & $1.38(1.15-1.64)^{* * *}$ & $1.09(0.91-1.31)$ \\
\hline \multicolumn{6}{|l|}{ CVD } \\
\hline No & 17,765 & 1622 & 9.1 & 1.0 (Reference) & 1.0 (Reference) \\
\hline Yes & 138 & 17 & 12.3 & $1.47(0.91-2.36)$ & $1.01(0.62-1.65)$ \\
\hline \multicolumn{6}{|c|}{ HAART during follow-up period } \\
\hline No & 5173 & 120 & 2.3 & 1.0 (Reference) & 1.0 (Reference) \\
\hline Yes & 12,730 & 1519 & 11.9 & $1.43(1.29-1.59)^{* * *}$ & $1.29(1.15-1.44)^{* * *}$ \\
\hline
\end{tabular}

Note. ${ }^{*} P<0.05 * * * P<0.001 ; * * *<0.001$

Abbreviation: AIDS acquired immunodeficiency syndrome, CHF chronic heart failure, $C l$ confidence intervals, CKD chronic kidney disease, COPD chronic obstructive pulmonary disease, CVD cardiovascular disease, DM diabetes mellitus, HAART highly active antiretroviral therapy, HR hazard ratios, PWID people who injected drugs

ancludes those exposed to blood products, mother-to-child transmission, and unknown exposures

cells $/ \mathrm{mm}^{3}$ in $2010,<500$ cells $/ \mathrm{mm}^{3}$ in 2013 , and in all patients, regardless of CD4 count, in 2016), an HIV case management program since 2007, and the employment of a single tablet regimen (STR) in HAART since 2016. We believe that AIDS prevalence during the follow-up period can be decreased substantially with HAART initiation for all patients and with STR implementation.

However, unlike in the sexual contact population, the rapid increase in AIDS incidence trends during the followup period among PWIDs ( $P$ for trend $<0.001$ ) should be cautiously monitored (Fig. 3b). This increasing trend among PWIDs may be attributable to suboptimal adherence to HAART among prison inmates [47], a higher rate of HIV-care discontinuity [48-50], and deferral of HAART by physicians [51]. Considering the sharp decrease in adherence to ART after release of incarcerated PWIDs [52], treatment of addiction and HIV infection at imprisonment and after release is critical for improving the continuity of post-release care [53]. We also identified chronic kidney disease as a risk factor for AIDS during the follow-up (Table 3). These results are likely attributable to the defective immune system through both immune activation and immune suppression [54], which might result in the reactivation of Mycobacterium tuberculosis or other AIDSdefining opportunistic infections [55-57]. In summary, given the diversity of care needs of the various HIV-at-risk populations, identification of the modifiable factors associated with AIDS incidence after linking to the HIV care is vital to better customize the HIV-care strategies for HIVat-risk populations in Taiwan.

The major strength of the present study was its nationwide scope and population-based design combined with the long and nearly complete follow-up. The populationbased design minimized selection and referral biases. The findings are critical for public health policies with regard to AIDS control, and may be generalized to Asia-Pacific and North American countries, which face similar HIV epidemics. However, the study had some limitations. First, the data used was limited to data reported to TCDC and NHIRD by primary physicians. Second, whether unmasking of the type of opportunistic illnesses after HAART contributed to AIDS incidence after HAART was not ascertained.

\section{Conclusions}

The results revealed that $27.4 \%$ patients developed AIDS during the cohort periods, with a majority developing at presentation, which reinforces the importance of identifying HIV infections as early as possible. The disparities in AIDS incidence trends at presentation and during followup in various HIV-at-risk populations can be explained by different sociodemographic variables associated with HIV exposure and the influence of the adopted HIV prevention strategies. These results suggest an urgent need for more active offering of HIV testing among sexual contact groups, with different policies tailored for gbMSMs (increased risk perception, removal of stigma and discrimination, protection of confidentiality, and elimination of structural barrier to HIV testing) and heterosexuals (implement of HIV home-based and self-testing kits). After linking to the HIV care, differentiated care for specific populations is required to better customize HIV-care strategies, especially for PWIDs (increased adherence to HIV care and HAART, especially after release, and increase willing of prescription of HAART by physicians). 


\section{Abbreviations}

AIDS: Acquired immunodeficiency syndrome; CHF: Chronic heart failure; CKD: Chronic kidney disease; COPD: Chronic obstructive pulmonary disease; CVD: Cardiovascular disease; DM: Diabetes mellitus; gbMSM: Gay, bisexual, and men who have sex with men; HAART: Highly active antiretroviral therapy; HR: Hazard ratio; IQR: Interquartile range; LP: Late presentation; NDSS: Notifiable Diseases Surveillance System; NHIRD: National Health Insurance Research Database; NTD: New Taiwan Dollars; OR: Odds ratio; PWID: Intravenous drug user; SD: Standard deviation; TCDC: Taiwan Centers for Disease Control; VCT: Voluntary counseling and testing

\section{Acknowledgments}

The authors would like to thank Enago (http://www.enago.tw) for the English language review.

\section{Funding}

This work was supported by a grant from the Center for Infectious Disease and Cancer Research, Kaohsiung Medical University (KMUTP105-E01), a grant from Kaohsiung Medical University Research Foundation (105KMUOR02), and a grant from Taiwan Centers for Disease Control (MOHW 106-CDC-C-114000115). The content of this publication is solely the responsibility of the authors and does not necessarily represent the official view of any government or institution mentioned above.

\section{Availability of data and materials}

Both TCDC-operated NDSS and NHIRD databases are not publicly available, and restrictions apply to the availability of the databases. Only analyzed data that are de-identified are released to the researchers. All data containing relevant information to support the study findings are provided in the manuscript.

\section{Authors' contributions}

CYL participated in study inception and design, data collection and analysis, and the drafting of manuscript. IAJ participated in study design, data collection and analysis, and the critical review of manuscript. YCL participated in study design and data collection and analysis. YFY participated in study design and data collection and analysis. PHC participated in study design and data collection and analysis. MC participated in study design and data collection and analysis. YL participated in study design, data collection and analysis, and statistical analysis. YMC participated in study inception and design, data collection and analysis, and the critical review of manuscript. All authors have read and approved the final manuscript.

\section{Ethics approval and consent to participate}

This study was approved by the ethics committee of Kaohsiung Medical University Hospital [KMUHIRB-SV (II)-20170043], and it adhered to the principles of the Declaration of Helsinki. Because the data were analyzed anonymously, the ethical committee waived the need for written consent.

\section{Competing interests}

The authors declare that they have no competing interests.

\section{Publisher's Note}

Springer Nature remains neutral with regard to jurisdictional claims in published maps and institutional affiliations.

\section{Author details}

'Division of Infectious Diseases, Department of Internal Medicine, Kaohsiung Medical University Hospital, Kaohsiung Medical University, Kaohsiung, Taiwan. ${ }^{2}$ Graduate Institute of Medicine, Kaohsiung Medical University, Kaohsiung, Taiwan. ${ }^{3}$ Center for Infectious Disease and Cancer Research (CICAR), Kaohsiung Medical University, No.100, Tzyou 1st Road, Kaohsiung 807, Taiwan. ${ }^{4}$ Department and Institute of Public Health, National Yang-Ming University, Taipei, Taiwan. ${ }^{5}$ Department of Health Risk Management, China Medical University, Taichung, Taiwan. ${ }^{6}$ Section of Infectious Diseases, Taipei City Hospital, Taipei, Taiwan. ${ }^{7}$ School of Medicine, National Yang-Ming University, Taipei, Taiwan. ${ }^{8}$ Department of Health and Welfare, College of City Management, University of Taipei, Taipei, Taiwan. ${ }^{9}$ Center for Prevention and Treatment of Occupational Injury and Diseases, Taipei Veterans General Hospital, Taipei, Taiwan. ${ }^{10}$ Division of Clinical Toxicology and Occupational
Medicine, Department of Medicine, Taipei Veterans General Hospital, Taipei, Taiwan. ${ }^{11}$ Department of Urology, Mackay Memorial Hospital, Taipei, Taiwan. ${ }^{12}$ Department of Cosmetic Applications and Management, Mackay Junior College of Medicine, Nursing and Management, Taipei, Taiwan.

${ }^{13}$ Department of Microbiology and Institute of Medical Research, College of Medicine, Kaohsiung Medical University, Kaohsiung, Taiwan.

Received: 3 December 2017 Accepted: 24 April 2018

Published online: 03 May 2018

\section{References}

1. Group ISS. Initiation of antiretroviral therapy in early asymptomatic HIV infection. N Engl J Med. 2015;2015:795-807.

2. Legarth RA, Ahlstrom MG, Kronborg G, Larsen CS, Pedersen C, Pedersen G, et al. Long-term mortality in HIV-infected individuals 50 years or older: a nationwide, population-based cohort study. J Acquir Immune Defic Syndr. 2016;71:213-8.

3. Cheng W, Tang W, Han Z, Tangthanasup TM, Zhong F, Qin F, et al. Late presentation of HIV infection: prevalence, trends, and the role of HIV testing strategies in Guangzhou, China, 2008-2013. Biomed Res Int. 2016;2016: 1631878.

4. Jeong SJ, Italiano C, Chaiwarith R, Ng OT, Vanar S, Jiamsakul A, et al. Late presentation into care of HIV disease and its associated factors in Asia: results of TAHOD. AIDS Res Hum Retrovir. 2016:32:255-61.

5. Mocroft A, Lundgren JD, Sabin ML, Monforte A, Brockmeyer N, Casabona J, et al. Risk factors and outcomes for late presentation for HIV-positive persons in Europe: results from the Collaboration of Observational HIV Epidemiological Research Europe Study (COHERE). PLoS Med. 2013;10: e1001510.

6. Honge BL, Jespersen S, Aunsborg J, Mendes DV, Medina C, da Silva TD, et al. High prevalence and excess mortality of late presenters among HIV-1, HIV-2 and HIV-1/2 dually infected patients in Guinea-Bissau - a cohort study from West Africa. Pan Afr Med J. 2016:25:40.

7. Sabin CA, Smith CJ, Gumley H, Murphy G, Lampe FC, Phillips AN, et al. Late presenters in the era of highly active antiretroviral therapy: uptake of and responses to antiretroviral therapy. AIDS. 2004;18:2145-51.

8. Sterne JA, May M, Costagliola D, de Wolf F, Phillips AN, Harris R, et al. Timing of initiation of antiretroviral therapy in AIDS-free HIV-1-infected patients: a collaborative analysis of 18 HIV cohort studies. Lancet. 2009;373: 1352-63.

9. Skarbinski J, Rosenberg E, Paz-Bailey G, Hall HI, Rose CE, Viall AH, et al. Human immunodeficiency virus transmission at each step of the care continuum in the United States. JAMA Intern Med. 2015;175:588-96.

10. Marks G, Crepaz N, Janssen RS. Estimating sexual transmission of HIV from persons aware and unaware that they are infected with the virus in the USA. AIDS. 2006;20:1447-50.

11. Guillon M, Celse M, Geoffard PY. Economic and public health consequences of delayed access to medical care for migrants living with HIV in France. Eur J Health Econ. 2018;19:327-40.

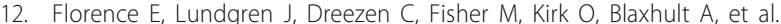
Factors associated with a reduced CD4 lymphocyte count response to HAART despite full viral suppression in the EuroSIDA study. HIV Med. 2003:4:255-62.

13. Centers for Disease Control DoH, R.O.C. (Taiwan). HIV/AIDS, http://www.cdc. gov.tw/english/info.aspx?treeid=e79c7a9e1e9b1cdf\&nowtreeid= e02c24f0dacdd729\&tid=7D01A79F5FD3B63D. Accessed 10 Nov 2017.

14. Lin T, Chen $\mathrm{CH}$, Chou P. Effects of combination approach on harm reduction programs: the Taiwan experience. Harm Reduct J. 2016;13:23.

15. Yang CH, Huang YF, Hsiao CF, Yeh YL, Liou HR, Hung CC, et al. Trends of mortality and causes of death among HIV-infected patients in Taiwan, 1984-2005. HIV Med. 2008:9:535-43.

16. Lin KY, Cheng CY, Li CW, Yang CJ, Tsai MS, Liu CE, et al. Trends and outcomes of late initiation of combination antiretroviral therapy driven by late presentation among HIV-positive Taiwanese patients in the era of treatment scale-up. PLoS One. 2017:12:e0179870.

17. Centers for Disease Control. 1993 revised classification system for HIV infection and expanded surveillance case definition for AIDS among adolescents and adults. Morb Mortal Wkly Rep. 1992;41.

18. Cheng TM. Taiwan's new national health insurance program: genesis and experience so far. Health Aff (Millwood). 2003;22:61-76. 
19. Yen YF, Jen IA, Chen M, Lan YC, Lee CY, Chuang PH, et al. HIV infection increases the risk of incident psoriasis: a nationwide population-based cohort study in Taiwan. J Acquir Immune Defic Syndr. 2017;75:493-9.

20. Beyrer C, Baral SD, van Griensven F, Goodreau SM, Chariyalertsak S, Wirtz AL, et al. Global epidemiology of HIV infection in men who have sex with men. Lancet. 2012;380:367-77.

21. Althoff KN, Gange SJ, Klein MB, Brooks JT, Hogg RS, Bosch RJ, et al. Late presentation for human immunodeficiency virus care in the United States and Canada. Clin Infect Dis. 2010;50:1512-20.

22. Centers for Disease Control DoH, R.O.C. (Taiwan). Centers for Disease Control Annual Report. http://www.cdc.gov.tw/infectionreport. aspx?nowtreeid=61AB37D12031B95A\&treeid=075874DC882A5BFD. Accessed 10 Nov 2017

23. Cherutich P, Kaiser R, Galbraith J, Williamson J, Shiraishi RW, Ngare C, et al. Lack of knowledge of HIV status a major barrier to HIV prevention, care and treatment efforts in Kenya: results from a nationally representative study. PLoS One. 2012;7:e36797.

24. Kalichman SC, Simbayi LC. HIV testing attitudes, AIDS stigma, and voluntary HIV counselling and testing in a black township in cape town, South Africa. Sex Transm Infect. 2003;79:442-7.

25. Creek TL, Ntumy R, Seipone K, Smith M, Mogodi M, Smit M, et al. Successful introduction of routine opt-out HIV testing in antenatal care in Botswana. J Acquir Immune Defic Syndr. 2007:45:102-7.

26. Centers for Disease Control DoH, R.O.C. (Taiwan). Designated HIV/AIDS Hospitals. https://www.syndriver.com/portal/\#/sharing/ a725aee3b57145ab822ad96bf77d98bf. Accessed 10 Nov 2017

27. O'Connell S, Enkelmann J, Sadlier C, Bergin C. Late HIV presentation missed opportunities and factors associated with a changing pattern over time. Int J STD AIDS. 2017;28:814-21.

28. Finlayson TJ, Le B, Smith A, Bowles $K$, Cribbin M, Miles I, et al. HIV risk, prevention, and testing behaviors among men who have sex with mennational HIV behavioral surveillance system, 21 U.S. cities, United States, 2008. MMWR Surveill Summ. 2011;60:1-34

29. Sionean C, Le BC, Hageman K, Oster AM, Wejnert C, Hess KL, et al. HIV risk, prevention, and testing behaviors among heterosexuals at increased risk for HIV infection-national HIV behavioral surveillance system, 21 U.S. cities, 2010. MMWR Surveill Summ. 2014;63:1-39.

30. Persson A, Brown G, McDonald A, Korner $\mathrm{H}$. Transmission and prevention of HIV among heterosexual populations in Australia. AIDS Educ Prev. 2014;26: 245-55.

31. Robinson WT, Zarwell M, Gruber D. Preferences for home-based HIV testing among heterosexuals at increased risk for HIV/AIDS: New Orleans, Louisiana, 2013. J Acquir Immune Defic Syndr. 2017;75(Suppl 3):S352-6.

32. Centers for Disease Control DoH, R.O.C. (Taiwan). Centers for Disease Control Annual Report 2017. http://61.57.41.133/uploads/files/201708/ 00a53329-34ba-4194-97f7-81480c446cbe.pdf. Accessed 10 Nov 2017.

33. Chen YJ, Lee CM, Chen M, Chuang SY, Liu HF, Wong WW, et al. Molecular epidemiology of HIV-1 infection in Taiwan from 2005 to 2008: further spread of CRF07_BC and emergence of CRF07_BC/subtype B dual infection. J Acquir Immune Defic Syndr. 2012;59:438-46.

34. Lin PH, Lai CC, Yang JL, Huang HL, Huang MS, Tsai MS, et al. Slow immunological progression in HIV-1 CRF07_BC-infected injecting drug users. Emerg Microbes Infect. 2013;2:e83.

35. Yang CH, Yang SY, Shen MH, Kuo HS. The changing epidemiology of prevalent diagnosed HIV infections in Taiwan, 1984-2005. Int J Drug Policy. 2008;19:317-23.

36. Camoni L, Raimondo M, Regine V, Salfa MC, Suligoi B. Late presenters among persons with a new HIV diagnosis in Italy, 2010-2011. BMC Public Health. 2013;13:281.

37. Ward EG, Disch WB, Schensul JJ, Levy JA. Understanding low-income, minority older adult self-perceptions of HIV risk. J Assoc Nurses AIDS Care. 2011:22:26-37

38. Chiao EY, Ries KM, Sande MA. AIDS and the elderly. Clin Infect Dis. 1999:28:740-5

39. Zingmond DS, Kilbourne AM, Justice AC, Wenger NS, Rodriguez-Barradas M, Rabeneck $\mathrm{L}$, et al. Differences in symptom expression in older HIV-positive patients: the veterans aging cohort 3 site study and HIV cost and service utilization study experience. J Acquir Immune Defic Syndr. 2003;33(Suppl 2):S84-92.

40. Illa L, Brickman A, Saint-Jean G, Echenique M, Metsch L, Eisdorfer C, et al. Sexual risk behaviors in late middle age and older HIV seropositive adults. AIDS Behav. 2008;12:935-42.
41. Sood N, Wagner Z, Jaycocks A, Drabo E, Vardavas R. Test-and-treat in Los Angeles: a mathematical model of the effects of test-and-treat for the population of men who have sex with men in Los Angeles County. Clin Infect Dis. 2013;56:1789-96.

42. Seth $P$, Wang G, Collins NT, Belcher L. Identifying new positives and linkage to HIV medical care-23 testing site types, United States, 2013. MMWR Morb Mortal Wkly Rep. 2015;64:663-7.

43. Branson BM, Handsfield HH, Lampe MA, Janssen RS, Taylor AW, Lyss SB, et al. Revised recommendations for HIV testing of adults, adolescents, and pregnant women in health-care settings. MMWR Recomm Rep. 2006;55: 1-17. quiz CE11-14

44. Leitinger D, Ryan KE, Brown G, Pedrana A, Wilkinson AL, Ryan C, et al. Acceptability and HIV prevention benefits of a peer-based model of rapid point of care HIV testing for Australian gay, bisexual and other men who have sex with men. AIDS Behav. 2018:22:178-89.

45. Lazarus JV, Hoekstra M, Raben D, Delpech V, Coenen T, Lundgren JD. The case for indicator condition-guided HIV screening. HIV Med. 2013;14:445-8.

46. Klein D, Hurley LB, Merrill D, Quesenberry CP Jr. Review of medical encounters in the 5 years before a diagnosis of HIV-1 infection: implications for early detection. J Acquir Immune Defic Syndr. 2003;32:143-52.

47. Uthman OA, Oladimeji O, Nduka C. Adherence to antiretroviral therapy among HIV-infected prisoners: a systematic review and meta-analysis. AIDS Care. 2017;29:489-97.

48. Rebeiro PF, Abraham AG, Horberg MA, Althoff KN, Yehia BR, Buchacz K, et al. Sex, race, and HIV risk disparities in discontinuity of HIV care after antiretroviral therapy initiation in the United States and Canada. AIDS Patient Care STDs. 2017;31:129-44.

49. Bitew BD, Berehane Y, Getahun E, Abyu D. Determinants of none-adherence to antiretroviral therapy among HIV-infected adults in Arba Minch General Hospital, Gamo Gofa Zone, Southern Ethiopia: a case control study. Am J Health Res. 2014:2:234-40.

50. Wasti SP, Simkhada P, Randall J, Freeman JV, Van Teijlingen E. Factors influencing adherence to antiretroviral treatment in Nepal: a mixedmethods study. PLoS One. 2012;7:e35547.

51. Ferro EG, Culbert GJ, Wickersham JA, Marcus R, Steffen AD, Pauls HA, et al. Physician decisions to defer antiretroviral therapy in key populations: implications for reducing human immunodeficiency virus incidence and mortality in Malaysia. Open Forum Infect Dis. 2017;4:ofw219.

52. Iroh PA, Mayo H, Nijhawan AE. The HIV care cascade before, during, and after incarceration: a systematic review and data synthesis. Am J Public Health. 2015;105:e5-16.

53. Kouyoumdjian FG, Mclsaac KE, Liauw J, Green S, Karachiwalla F, Siu W, et al. A systematic review of randomized controlled trials of interventions to improve the health of persons during imprisonment and in the year after release. Am J Public Health. 2015;105:e13-33.

54. Sharif MR, Chitsazian Z, Moosavian M, Raygan F, Nikoueinejad H, Sharif AR, et al. Immune disorders in hemodialysis patients. Iran J Kidney Dis. 2015;9:84-96.

55. El Amrani M, Asserraji M, Bahadi A, El Kabbaj D, Benyahia M. Tuberculosis in hemodialysis. Medecine et Sante Tropicales. 2016;26:262-6.

56. Inaba A, Okada A, Yoshida T, Itoyama S, Nakai T, Hisada T, et al. Disseminated Cryptococcosis with rapidly growing lung nodules in an endstage renal disease patient. Intern Med. 2017;56:377-80.

57. Mansouri L, Paulsson JM, Moshfegh A, Jacobson SH, Lundahl J. Leukocyte proliferation and immune modulator production in patients with chronic kidney disease. PLoS One. 2013:8:e73141.

\section{Ready to submit your research? Choose BMC and benefit from:}

- fast, convenient online submission

- thorough peer review by experienced researchers in your field

- rapid publication on acceptance

- support for research data, including large and complex data types

- gold Open Access which fosters wider collaboration and increased citations

- maximum visibility for your research: over $100 \mathrm{M}$ website views per year

At BMC, research is always in progress.

Learn more biomedcentral.com/submissions 